\title{
Relationship between quantitative parameters of lumbar vertebral perfusion and bone mineral density (BMD) in postmenopausal women
}

\author{
Zhenhuan Huang ${ }^{1, A-D, F}$, Qi Lin ${ }^{1, E, F}$, Jianwen Wang ${ }^{1, B}$, Zejuan Zhan ${ }^{1, C}$, Xuezhao Tu ${ }^{2, A, C}$ \\ ${ }^{1}$ Department of Radiology, First Hospital of Longyan of Fujian Medical University, China \\ 2 Department of Orthopedics, First Hospital of Longyan of Fujian Medical University, China \\ A - research concept and design; $\mathrm{B}$ - collection and/or assembly of data; $\mathrm{C}$ - data analysis and interpretation; \\ $D$ - writing the article; $E$ - critical revision of the article; $F$ - final approval of the article
}

Address for correspondence

Xuezhao Tu

E-mail: xuezhaotu@sina.com

Funding sources

None declared

Conflict of interest

None declared

Received on December 26, 2017

Reviewed on January 4, 2018

Accepted on August 9, 2018

Published online on April 13, 2019

Cite as

Huang Z, Lin Q, Wang J, Zhan Z, Tu X. Relationship between quantitative parameters of lumbar vertebral perfusion and bone mineral density (BMD) in postmenopausal women. Adv Clin Exp Med. 2019;28(8):1005-1011.

doi:10.17219/acem/94150

DOI

10.17219/acem/94150

Copyright

Copyright by Author(s)

This is an article distributed under the terms of the

Creative Commons Attribution Non-Commercial License

(http://creativecommons.org/licenses/by-nc-nd/4.0/)

\section{Abstract}

Background. Dynamic contrast-enhanced magnetic resonance imaging (DCE-MRI) is a noninvasive method to evaluate the microcirculation of bone marrow in local tissue, which will be a new tool for the diagnosis of osteoporosis.

Objectives. To investigate the relationship between quantitative perfusion parameters ( $K^{\text {trans }}, K_{\text {ep }}$ and $V_{e}$ ) and bone mineral density (BMD) in postmenopausal women.

Material and methods. The subjects were divided into 3 groups according to T value: normal bone mass group ( $T$ value $\geq-1.0)$; bone loss group $(-2.5<T<-1.0)$; and osteoporosis group $(T \leq-2.5)$. $K^{\text {trans }}$, $K_{\text {ep }}$ and $V_{e}$ of the lumbar spine were measured using quantitative DCE-MRI. The relationship between these parameters and age was analyzed.

Results. Bone mineral density of the lumbar spine and femoral neck gradually decreased with age. The values of $K^{\text {trans }}, K_{\text {ep }}$ and $V_{e}$ significantly decreased with age. The values of $K^{\text {trans }}, K_{\text {ep }}$ and $V_{e}$ of the lumbar vertebrae in the osteoporosis group were lower than those in the bone loss and normal bone mass group. Bone mineral density was positively correlated with the $K^{\text {trans }}$ and $V_{e}$ of the lumbar vertebrae.

Conclusions. The incidences of bone loss and osteoporosis increased with age. The measurement of BMD was conducive to early diagnosis of osteoporosis. $K^{\text {trans }}, K_{\text {ep }}$ and $V_{e}$ values of the lumbar vertebra decreased with age, and have a positive correlation with lumbar BMD. The value of DCE-MRI may play a role in the diagnostic algorithm of osteoporosis.

Key words: osteoporosis, bone mineral density (BMD), quantitative dynamic contrast-enhanced magnetic resonance (DCE-MRI), quantitative parameters 


\section{Introduction}

Osteoporosis is a systemic skeletal disease characterized by bone loss, microstructural degradation with a resulting increase in bone fragility and, as a consequence, susceptibility to fracture. ${ }^{1}$ Primary osteoporosis (including in the postmenopausal and elderly women) is a physiological degeneration that inevitably occurs with the growth of age. Osteoporosis-induced pain, height shortening, humpback, fractures, and other complications seriously reduce the quality of life of patients. Patients are also under several economic burdens due to the pain. Therefore, osteoporosis has become a serious public health problem in the world.

It is widely known that bone biochemical markers are one of the methods for assessing bone metabolism in humans, ${ }^{2-5}$ but their use has been limited to providing comprehensive information about the overall bone response, which does not reflect changes of the hip or other specific parts. Bone mineral density (BMD) is still a gold standard in the diagnosis of osteoporosis, ${ }^{6}$ but the strength of bone is affected not only by BMD, but also by bone mass (bone mass is an important factor of the strength of bone). Therefore, the determination of BMD also has some limitations. ${ }^{7-10}$

Researchers have not yet reached a consensus on the pathogenesis of osteoporosis. The main hypotheses include decreasing sex hormones, excess fat and bone marrow perfusion. ${ }^{11,12}$ In recent years, decreasing blood flow in bone marrow has also been considered as an important factor of osteoporosis. Dynamic contrast-enhanced magnetic resonance imaging (DCE-MRI) is a noninvasive method of evaluating the microcirculation of bone marrow in local tissue, which can be a new tool for the diagnosis of osteoporosis. Through the analysis of the quantitative parameters $\left(K^{\text {trans }}, K_{e p}\right.$ and $V_{e}$ ) of lumbar vertebrae bone marrow perfusion in 197 postmenopausal women, the changes of BMD of the lumbar spine with age were analyzed.

\section{Material and methods}

\section{Study subjects}

A total of 197 postmenopausal women with ages ranging from 47 to 86 years were examined from May 2014 to August 2016. The dual-energy X-ray absorptiometry (DXA) and DCE-MRI examinations in osteoporosis were performed in the First Hospital of Longyan of Fujian Medical University, China. Inclusion criteria were as follows: (1) no deformity of the lumbar spine or hip; (2) no tumors, metastases or other diseases which affect the metabolism of bone; (3) no history of surgery or radiotherapy and chemotherapy; (4) no drugs taken that affect bone metabolism or the excretion of urinary creatinine;
(5) no contraindications for MRI. This study was approved by the ethics committee of the First Hospital of Longyan of Fujian Medical University, China. All participants signed informed consent of the corresponding rights and obligations.

\section{DXA inspection}

Bone mineral density of the anteroposterior lumbar spine and the femoral neck were measured with DXA (DPX-L, Lunar; GE Healthcare, Chicago, USA). The unit of measure was $\mathrm{g} / \mathrm{cm}^{2}$. Manual errors, which included postural swings and other technical problems, were eliminated by technical experts during the measurements. Standard periosteal type instrumentation was used before the measurement. The coefficient of variation of the instrument was less than $1 \%$. The results of the DXA measurements were considered as the criteria for grouping. The subjects were divided into 3 groups according to $\mathrm{T}$ value: normal bone mass group ( $\mathrm{T}$ value $\geq-1.0)$; bone loss group $(-2.5<\mathrm{T}<-1.0)$; and osteoporosis group $(\mathrm{T} \leq-2.5)$. The division was based on the diagnostic criteria of postmenopausal osteoporosis established by the World Health Organization (WHO) in 1994.

\section{MRI examination}

All subjects underwent conventional scanning and DCEMRI examination on Signa HDi $1.5 \mathrm{~T}$ superconducting MRI equipment (GE Healthcare, Chicago, USA). Conventional scans were used to observe the morphology and signal intensity of the lumbar vertebrae, including sagittal FSE-XL sequence T1WI (TR $450 \mathrm{~ms}$, TE $14.4 \mathrm{~ms}$, matrix $320 \times 192)$ and sagittal FRFSE-XL sequence T2WI (TR $2500 \mathrm{~ms}$, TE $110 \mathrm{~ms}$, matrix $320 \times 224$ ). The scanning sequence had a layer thickness of $4 \mathrm{~mm}$, an interlayer pitch of $0.5 \mathrm{~mm}$ and a FOV of $35 \mathrm{~mm}$, which scanned 11 layers in total.

DCE-MRI was set as LAVA sequence (T1WI: TR $3.5 \mathrm{ms,}$ TE $1.2 \mathrm{~ms}$, FOV $35 \mathrm{~mm}$ ), matrix $256 \times 160$, and slice thickness $5 \mathrm{~mm}$. The conventional scan, which can show the dynamic central lumbar vertebral level for the enhancement was chosen. The layer (Gd-BOPTA) was injected intravenously at a dose of $0.1 \mathrm{mmol} / \mathrm{kg}$ and a rate of $5 \mathrm{~mL} / \mathrm{s}$. Analysis software from the workstation was used to draw the region of interest (ROI). The ROI included cancellous bone part of the whole vertebral body, more than $3 \mathrm{~mm}$ from the edge of the vertebral body, and avoiding bone island, posterior venous plexus and so on. The arterial input function (AIF) was calculated using the pharmacokinetic blood dual compartment model (Tofts model) to get the quantitative parameters. The quantitative parameters can reflect microvascular permeability, tissue perfusion and extravascular extracellular space directly. The volume constant $\left(\mathrm{K}^{\text {trans }}\right)$ and the rate constant $\left(\mathrm{K}_{\mathrm{ep}}, \mathrm{K}_{\mathrm{ep}}=\mathrm{K}^{\text {trans }} / \mathrm{V}_{\mathrm{e}}\right)$ of the contrast agent from plasma to extravascular 
extracellular space (EES) represent the transfer constant $\left(\mathrm{K}^{\text {trans }}\right)$ and contrast agent from EES. $\mathrm{V}_{\mathrm{e}}$ represents the volume of EES per unit volume of tissue in $\mathrm{mL} / 100 \mathrm{~mL}$. $\mathrm{K}^{\text {trans }}$ represents the comparative dose of blood into the EES per unit volume of tissue per unit time, that is, volume capillary permeability-surface area product in $\mathrm{min}^{-1}$. $\mathrm{K}_{\mathrm{ep}}$ represents the comparative dose of EES returned to the blood vessel per unit time (the exchange rate of the contrast agent between the plasma and the EES gap) in $\mathrm{min}^{-1}$.

\section{Statistical analysis}

The diversification of BMD in the lumbar spine and femoral neck as well as the changes of $K^{\text {trans }}, K_{e p}$ and $V_{e}$ of the lumbar spine were analyzed in each age group using 2 samples to test. The diagnostic criterion of osteoporosis was $\mathrm{T} \leq 2.5$, which was used to calculate the bone mass reduction and the detection rate of osteoporosis in all age groups. The relationship between age, $\mathrm{T}$ value, $B M D$, and $K^{\text {trans }}, K_{e p}$ and $V_{e}$ of lumbar, was analyzed using analysis of variance (ANOVA) test in normal, bone loss and osteoporosis groups. To determine the relationship between $K^{\text {trans }}, K_{e p}$ and $V_{e}$ of the lumbar and age and BMD of lumbar, linear correlation was analyzed. A value of $\mathrm{p}<0.05$ represented a statistically significant difference. The data was analyzed using SPSS v. 16.0 software (SPSS Inc., Chicago, USA). Data was expressed as mean \pm standard deviation (SD) $(\mathrm{X} \pm \mathrm{s})$.

\section{Results}

\section{Comparison of bone mineral density between lumbar spine and femoral neck in all age groups}

The decrease of bone mass of the lumbar spine and femoral neck, and the rate of detection of osteoporosis are shown in Table 1. Bone mineral density of the lumbar spine and femoral neck gradually decreased with age. It decreased rapidly over 50 years of age and declined again at or after 70 years of age. There was no significant difference in BMD between lumbar vertebrae and femoral neck at the same age $(\mathrm{p}>0.05)$.

\section{Comparison of the decline of bone mass and detection rate of osteoporosis in all age groups}

$\mathrm{T} \leq 2.5$ is the diagnostic criterion for osteoporosis. The incidence of osteoporosis increased significantly with age, together with decreasing bone mass. People over 50 years of age will be at significantly increased risk of osteoporosis, which will be more emergent at each additional 10 years of age. After the age of 70, the increase of the incidence was further intensified, which will be increased by $15 \%$ or more in the development of osteoporosis. Occurrences in the lumbar appeared earlier than in the femoral neck. Therefore, a site examination of the lumbar could help find osteoporosis earlier.

\section{Comparison of the $\mathrm{K}^{\text {trans }}, \mathrm{K}_{\mathrm{ep}}$ and $\mathrm{V}_{\mathrm{e}}$ of lumbar in all age groups}

The parameters of $\mathrm{K}^{\text {trans }}, \mathrm{K}_{\mathrm{ep}}$ and $\mathrm{V}_{\mathrm{e}}$ of the lumbar spine were analyzed in each age group. The results showed that the values of $K^{\text {trans }}$ and $K_{\text {ep }}$ of the lumbar spine decreased gradually with age. $V_{e}$ of the lumbar also showed a significant downward trend (Table 2).

\section{Relationship analysis between $\mathrm{K}^{\text {trans }}, \mathrm{K}_{\mathrm{ep}}, \mathrm{V}_{\mathrm{e}}$ and age}

Linear correlation analysis of $\mathrm{K}^{\text {trans }}, \mathrm{K}_{\mathrm{ep}}$ and $\mathrm{V}_{\mathrm{e}}$ of the lumbar spine and age was performed using linear correlation with age as an independent variable. There was a negative

Table 2. Hemodynamics parameters of lumbar vertebrae in all age groups $(X \pm s)$

\begin{tabular}{|l|c|c|c|c|}
$\begin{array}{c}\text { Age groups } \\
\text { [years] }\end{array}$ & $\mathrm{n}$ & $\begin{array}{c}\mathrm{K}^{\text {trans }} \\
{\left[\mathrm{min}^{-1}\right]}\end{array}$ & $\begin{array}{c}\mathrm{K}_{\mathrm{ep}} \\
{\left[\mathrm{min}^{-1}\right]}\end{array}$ & $\begin{array}{c}\mathrm{V}_{\mathrm{e}} \\
{[\mathrm{mL} / 100 \mathrm{~mL}]}\end{array}$ \\
\hline $40 \sim$ & 5 & $1.123 \pm 0.192$ & $3.118 \pm 0.023$ & $0.358 \pm 0.021$ \\
\hline $50 \sim$ & 66 & $0.721 \pm 0.077^{*}$ & $3.000 \pm 0.100^{*}$ & $0.235 \pm 0.006^{*}$ \\
\hline $60 \sim$ & 72 & $0.514 \pm 0.039^{*}$ & $2.727 \pm 0.114^{*}$ & $0.184 \pm 0.003^{*}$ \\
\hline $70 \sim$ & 44 & $0.361 \pm 0.017^{*}$ & $2.459 \pm 0.112^{*}$ & $0.144 \pm 0.001^{*}$ \\
\hline $80 \sim$ & 10 & $0.213 \pm 0.005^{*}$ & $2.096 \pm 0.068^{*}$ & $0.100 \pm 0.001^{*}$ \\
\hline
\end{tabular}

The values between different groups were compared using ANOVA test; ${ }^{*} p<0.05$ vs 40 years age group.

Table 1. Bone mineral density (BMD) of lumbar vertebrae and femur neck and detection rate of osteoporosis in all age groups

\begin{tabular}{|c|c|c|c|c|c|c|c|}
\hline \multirow{2}{*}{$\begin{array}{c}\text { Age } \\
\text { group } \\
\text { [years] }\end{array}$} & \multirow[b]{2}{*}{$\mathrm{n}$} & \multirow{2}{*}{$\begin{array}{l}\text { BMD of lumbar vertebrae } \\
\qquad\left[\mathrm{g} / \mathrm{cm}^{2}\right], X \pm \mathrm{s}\end{array}$} & \multirow{2}{*}{$\begin{array}{l}\text { BMD of femoral neck } \\
{\left[\mathrm{g} / \mathrm{cm}^{2}\right], X \pm \mathrm{s}}\end{array}$} & \multicolumn{2}{|c|}{ Lumbar vertebrae } & \multicolumn{2}{|c|}{ Femur neck } \\
\hline & & & & $\begin{array}{c}\text { bone loss, } \\
n[\%]\end{array}$ & $\begin{array}{l}\text { osteoporosis, } \\
\text { n [\%] }\end{array}$ & $\begin{array}{l}\text { bone loss, } \\
\mathrm{n}[\%]\end{array}$ & $\begin{array}{l}\text { osteoporosis, } \\
n[\%]\end{array}$ \\
\hline $40 \sim$ & 5 & $1.112 \pm 0.093$ & $1.065 \pm 0.023$ & $2(40.0)$ & $0(0.0)$ & $1(20.0)$ & $0(0.0)$ \\
\hline $50 \sim$ & 66 & $0.841 \pm 0.028^{*}$ & $0.845 \pm 0.023^{*}$ & $22(33.3)$ & $18(27.3)^{*}$ & $20(30.3)$ & $14(21.2)^{*}$ \\
\hline $60 \sim$ & 72 & $0.745 \pm 0.021^{*}$ & $0.744 \pm 0.020^{*}$ & $26(36.1)$ & $32(44.4)^{*}$ & $30(41.7)$ & $26(34.7)^{*}$ \\
\hline $70 \sim$ & 44 & $0.646 \pm 0.013^{*}$ & $0.643 \pm 0.010^{*}$ & $6(13.7)$ & $33(75.0)^{*}$ & $14(31.8)$ & $25(56.8)^{*}$ \\
\hline $80 \sim$ & 10 & $0.559 \pm 0.003^{*}$ & $0.571 \pm 0.002^{*}$ & $1(10.0)$ & $9(90.0)^{*}$ & $2(20.0)$ & $8(80.0)^{*}$ \\
\hline
\end{tabular}

The values between different groups were compared using ANOVA test; ${ }^{*} p<0.05$ vs $40 \sim$ years age group. 
correlation between age and $\mathrm{K}^{\text {trans }}$ and $\mathrm{V}_{\mathrm{e}}$ of the lumbar spine. The correlation coefficients ( $\mathrm{r}$ ) were $0.907,0.913$ and 0.864 , respectively $(\mathrm{p}<0.05)$. These results are shown in Fig. 1.

\section{Morphometric differences \\ of dynamic enhancement curve of lumbar vertebrae in normal, bone loss and osteoporosis groups}

Compared with bone loss and normal groups, the quantitative dynamic enhancement curve of lumbar spine was more stable, and the $\mathrm{K}^{\text {trans }}$ value was lower in osteoporosis group. Meanwhile, the quantitative dynamic enhancement curve of lumbar spine and the $\mathrm{K}^{\text {trans }}$ value were the highest in osteoporosis group. These results are shown in Fig. 2.

\section{Comparison of $\mathrm{K}^{\text {trans }}$, $\mathrm{K}_{\mathrm{ep}}$ and $\mathrm{V}_{\mathrm{e}}$ of lumbar in each group}

According to the $\mathrm{T}$ value, 197 cases were divided into a normal group $(n=48)$, bone loss group $(n=57)$ and osteoporosis group $(\mathrm{n}=92)$. The BMD of lumbar vertebrae was $1.025 \pm 0.009 \mathrm{~g} / \mathrm{cm}^{2}, 0.778 \pm 0.000 \mathrm{~g} / \mathrm{cm}^{2}$ and $0.600 \pm 0.001 \mathrm{~g} / \mathrm{cm}^{2}$ in the above groups, respectively. Statistical significance was found in each group $(\mathrm{p}<0.01)$. In the osteoporosis group, $\mathrm{K}^{\text {trans }}$ value was $0.326 \pm 0.005 \mathrm{~min}^{-1}, \mathrm{~K}_{\mathrm{ep}}$ value was $2.344 \pm 0.030 \mathrm{~min}^{-1}$,
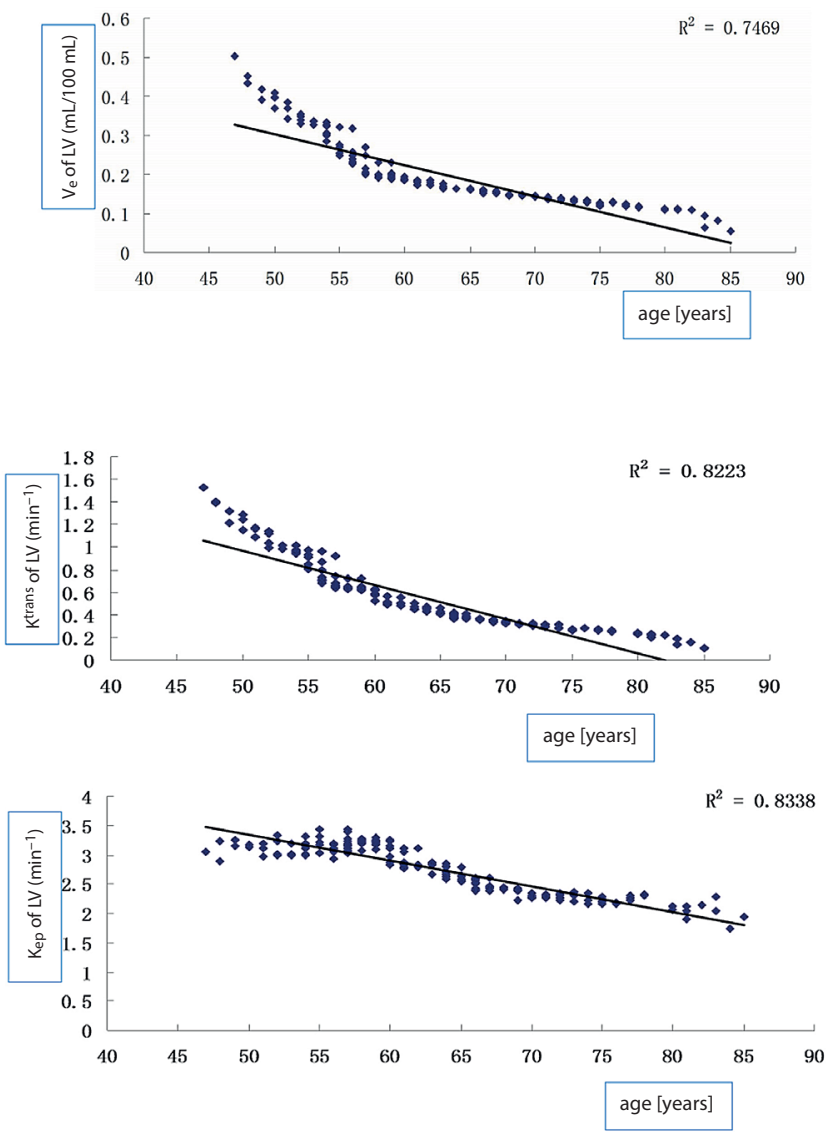

Fig. 1. Relationship analysis between $\mathrm{K}^{\text {trans }}, \mathrm{K}_{\mathrm{ep}}$ and $\mathrm{V}_{\mathrm{e}}$ values of lumbar vertebrae and age and $\mathrm{V}_{\mathrm{e}}$ value was $0.318 \pm 0.000 \mathrm{~mL} / 100 \mathrm{~mL}, \mathrm{p}<0.01$. In the bone loss group, $\mathrm{K}^{\text {trans }}$ value was $0.563 \pm 0.006 \mathrm{~min}^{-1}$, $\mathrm{K}_{\mathrm{ep}}$ value was $3.023 \pm 0.039 \mathrm{~min}^{-1}$ and $\mathrm{V}_{\mathrm{e}}$ value was $0.185 \pm 0.000 \mathrm{~mL} / 100 \mathrm{~mL}, \mathrm{p}<0.01$, and those values were lower than in the normal group $\left(\mathrm{K}^{\text {trans }} 0.961 \pm 0.048 \mathrm{~min}^{-1}\right.$, $\mathrm{K}_{\text {ep }} 3.150 \pm 0.018 \mathrm{~min}^{-1}$ and $\mathrm{V}_{\mathrm{e}} 0.306 \pm 0.005 \mathrm{~mL} / 100 \mathrm{~mL}$, $\mathrm{p}<0.01$, respectively). The values of $\mathrm{K}^{\text {trans }}, \mathrm{K}_{\mathrm{ep}}$ and $\mathrm{V}_{\mathrm{e}}$ parameters in the osteoporosis group were lower than in the bone loss group $(\mathrm{p}<0.01)$. These results are shown in Table 3.

\section{Correlation analysis between $\mathrm{K}^{\text {trans }}, \mathrm{K}_{\mathrm{ep}}$ and $\mathrm{V}_{\mathrm{e}}$, and bone mineral density of lumbar}

The linear correlation analysis of the correlation between $K^{\text {trans }}, K_{e p}$ and $V_{e}$ values of lumbar vertebrae and the BMD value of the lumbar spine was performed using a linear correlation method, with BMD value as an independent variable. There was a positive correlation between $B M D$ and the $K^{\text {trans }}, K_{e p}$ and $V_{e}$ values. Lumbar $K^{\text {trans }}, K_{e p}$ and $\mathrm{V}_{\mathrm{e}}$ values decreased together with lower lumbar BMD. The correlation coefficients $(\mathrm{R})$ were $0.969,0.818$ and 0.944 $(\mathrm{p}<0.05)$, respectively. These results are shown in Fig. 3.
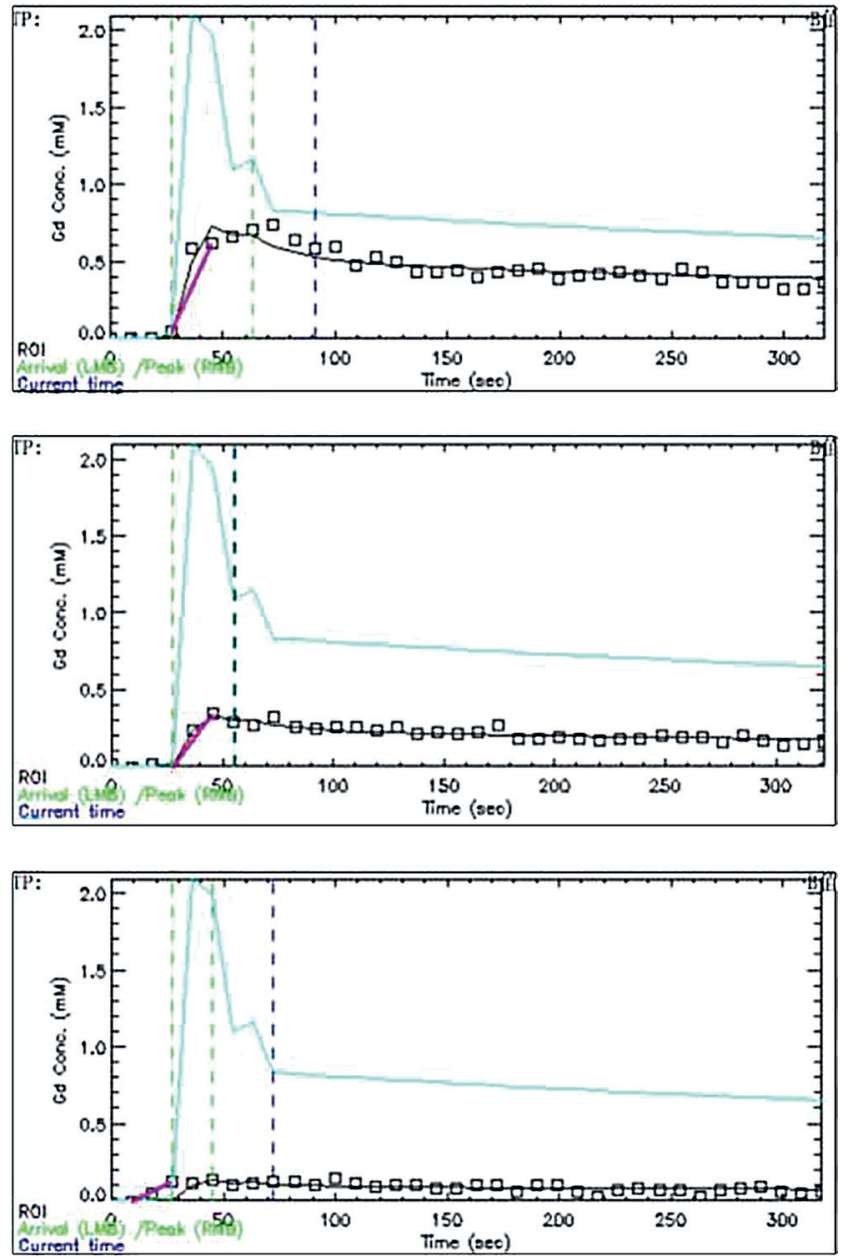

Fig. 2. Morphometric differences of dynamic enhancement curve of lumbar vertebrae with normal, bone loss and osteoporosis groups ( - normal group; B - bone loss group; C - osteoporosis group) 
Table 3. Comparison of the hemodynamics parameters and bone mineral density (BMD) of lumbar vertebrae in all age groups (X $\pm s)$

\begin{tabular}{|l|c|c|c|c|c|c|c|c|c|c|}
\multicolumn{1}{|c|}{ Groups } & $\mathrm{n}$ & Age [years $]$ & $\mathrm{T}$ & $\mathrm{BMD}\left[\mathrm{g} / \mathrm{cm}^{2}\right]$ & $\mathrm{K}^{\mathrm{trans}}\left[\mathrm{min}^{-1}\right]$ & $\mathrm{K}_{\mathrm{ep}}\left[\mathrm{min}{ }^{-1}\right]$ & $\mathrm{V}_{\mathrm{e}}[\mathrm{mL} / 100 \mathrm{~mL}]$ \\
\hline Normal & 48 & $57.077 \pm 6.685$ & $0.356 \pm 0.277$ & $1.025 \pm 0.009$ & $0.961 \pm 0.048$ & $3.150 \pm 0.018$ & $0.306 \pm 0.005$ \\
\hline Bone loss & 57 & $61.386 \pm 6.643^{*}$ & $-1.625 \pm 0.067^{*}$ & $0.778 \pm 0.000^{*}$ & $0.563 \pm 0.006^{*}$ & $3.023 \pm 0.039^{*}$ & $0.185 \pm 0.000^{*}$ \\
\hline Osteoporosis & 92 & $68.207 \pm 7.983^{*}+$ & $-2.989 \pm 0.047^{*}+$ & $0.600 \pm 0.001^{*}+$ & $0.326 \pm 0.005^{*}+$ & $2.344 \pm 0.030^{*}+$ & $0.318 \pm 0.000^{*}+$ \\
\hline
\end{tabular}

The values of different groups were compared using ANOVA test. ${ }^{*} p<0.01$ vs normal group; $\uparrow \mathrm{p}<0.01$ vs bone loss group.
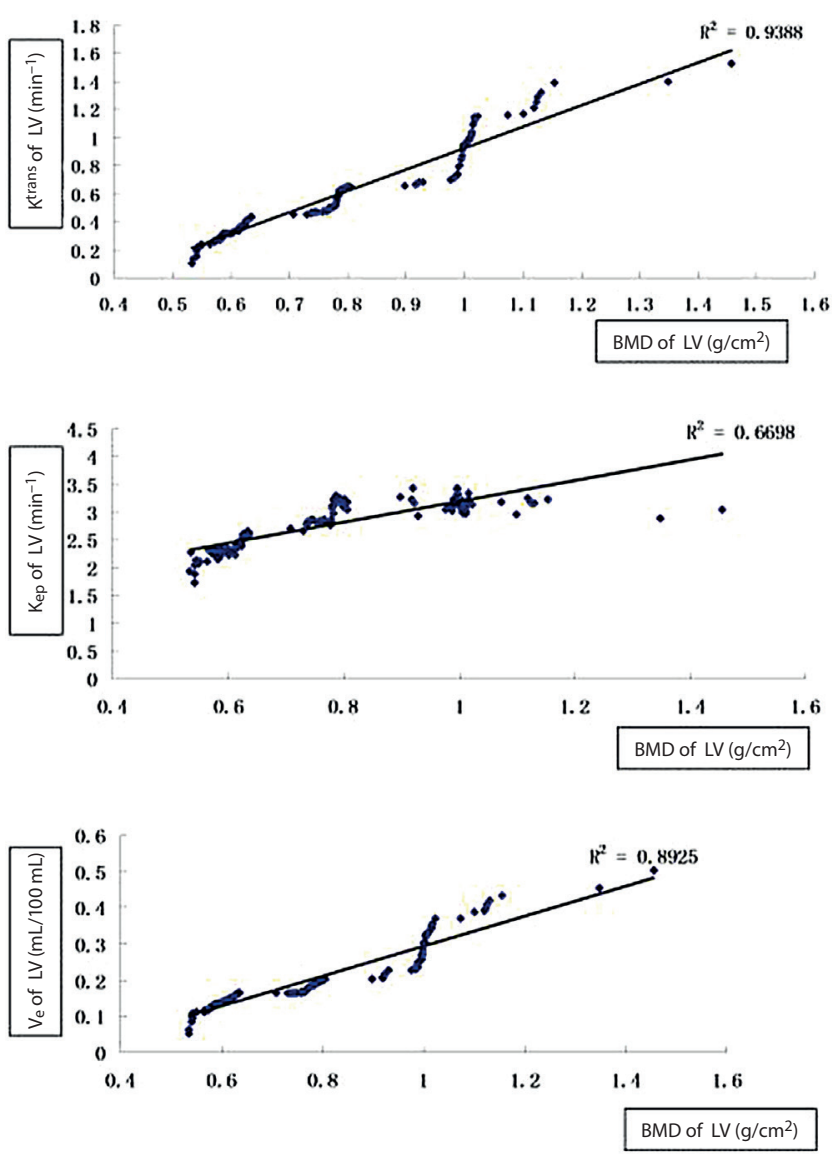

Fig. 3. Correlation analysis between $\mathrm{K}^{\text {trans }}, \mathrm{K}_{\mathrm{ep}}$ and $\mathrm{V}_{\mathrm{e}}$ values, and bone mineral density (BMD) of the lumbar

\section{Discussion}

By analyzing BMD of the lumbar spine and femoral neck in postmenopausal women, we found that BMD decreased significantly after the age of 50 . This may be because estrogen plays an important role in regulating bone metabolism in women. Postmenopausal women have lower estrogen levels, which would accelerated the resorption of bone. ${ }^{13}$ When people are over 70 years old, the reduction of BMD will be aggravated, which is related to the diversification of diet, decreased activity, and reduced vitamin D synthesis and conversion. All these reasons lead to accelerated bone loss. This study also found that the incidence of osteoporosis increased gradually with age. With each additional 10 years of age, osteoporosis increased by a more than $15 \%$ rate of development. Osteoporosis occurred in the lumbar earlier than the femoral neck. Therefore, the site of the lumbar for BMD testing could help find osteoporosis earlier.

In recent years, some scholars hypothesized that decreased bone marrow perfusion leads to osteoporosis. Bone marrow includes red and yellow bone marrow types. Red bone marrow has a rich vascular network made up of adipose tissue (40\%), water (40\%) and protein (20\%). Yellow bone marrow has little vascular network, with adipose tissue, water and protein accounting for $80 \%, 15 \%$ and $5 \%$, respectively. The proportion of red and yellow bone marrow gradually shifts from primarily red until it inverts into primarily yellow gradually with age. ${ }^{14,15}$ Because of the limited space for of bone marrow, excessive adipose tissue will oppress trabecular microvascular microcirculation. Therefore, age is a key factor of bone marrow perfusion level. In our study, $\mathrm{K}^{\text {trans }}, \mathrm{K}_{\mathrm{ep}}$ and $\mathrm{V}_{\mathrm{e}}$ values of the lumbar vertebrae of postmenopausal women gradually decreased with age. $K^{\text {trans }}, K_{e p}$ and $V_{e}$ values of the lumbar spine in patients older than 50 years of age were significantly lower than in younger people. The normal menopausal age was below 50. Postmenopausal women suffer dual factors, menopause and aging, which induces significant reduction of bone marrow perfusion. Figure 1 also shows a negative correlation between $\mathrm{K}^{\text {trans }}, \mathrm{K}_{\mathrm{ep}}$ and $\mathrm{V}_{\mathrm{e}}$ values of the lumbar, and age in postmenopausal women.

Primary osteoporosis is common among postmenopausal women and the elderly. The pathological features are decreased bone marrow unit area within the capillaries and blood sinus number, increased number of adipocytes and the volume, and increased bone mineral deposition decrease. ${ }^{16,17}$ Our results showed that there were positive correlations between $\mathrm{K}^{\text {trans }}, \mathrm{K}_{\mathrm{ep}}$ and $\mathrm{V}_{\mathrm{e}}$, and BMD of the lumbar spine in postmenopausal women. The correlation coefficients were $0.969,0.818$ and 0.944 , respectively. The decrease of $K^{\text {trans }}, K_{e p}$ and $V_{e}$ values was associated with BMD. We also found that $\mathrm{K}^{\text {trans }}, \mathrm{K}_{\mathrm{ep}}$ and $\mathrm{V}_{\mathrm{e}}$ values of lumbar vertebrae in the osteoporosis group were lower than in the normal group. The decrease in the osteoporosis group was the most significant and the dynamic enhancement curve was the smoothest. Decreased $K_{\mathrm{ep}}$ and $K^{\text {trans }}$ values suggest degradation of vascular function and decreased permeability of the vessel wall, while decreased $V_{e}$ value suggests that fat content increased and interstitial space decreased. These affect the supply of blood in bone tissue and are consistent with reports the literature. ${ }^{11,18-21}$

Interestingly, we also found that DCE-MRI can reflect the blood supply characteristics of local lumbar spine and hemodynamic changes. Through the intravenous 
contrast agent Gd-DTPA and changes in the local tissue magnetic field, the time-signal intensity curve obtained with the contrast agent can produce semi-quantitative parameters such as slope, maximum contrast enhancement rate and enhanced peak value. The time-signal intensity curve can also be obtained by post-processing quantitative parameters such as volume transfer constant $\left(\mathrm{K}^{\text {trans }}\right)$, extravascular extracellular volume fraction $\left(\mathrm{V}_{\mathrm{e}}\right)$ of the contrast agent permeating from the plasma to extravascular extracellular space (EES), and rate constants of return of the contrast agent from EES to plasma $\left(\mathrm{K}_{\mathrm{ep}}\right)$, $\mathrm{K}_{\mathrm{ep}}=\mathrm{K}^{\text {trans }} / \mathrm{V}_{\mathrm{e}}$. Some studies ${ }^{22}$ have found that in patients with osteoporosis, semi-quantitative MRI enhanced peak intensity decrease, and decreased BMD was significantly positively correlated. Ma et al. ${ }^{23}$ reported that the quantitative parameters $\mathrm{K}^{\text {trans }}$ and $\mathrm{V}_{\mathrm{e}}$ in the osteoporosis group were significantly lower than in the normal (control) group.

Another investigator found that there was a negative correlation between age, the bone marrow fat fraction (FF) value and quantitative parameters $\mathrm{K}^{\text {trans }}$ and $\mathrm{K}_{\mathrm{ep}}$, and semiquantitative parameters (fortified peak) in the population without osteoporosis. ${ }^{24} \mathrm{Zhu}$ et $\mathrm{al}^{25}$ found that $\mathrm{K}^{\text {trans }}$ and BMD decreased significantly 2 weeks after ovariectomy in rats, while $V_{e}$ decreased significantly 10 weeks after ovariectomy. There was a negative correlation between $\mathrm{K}_{\mathrm{ep}}$, FF value and BMD reduction. The relationship between $\mathrm{K}_{\text {ep }}$, FF and BMD is not clear. Wáng et $a{ }^{26}{ }^{26}$ reported that bilateral ovariectomy led to a rapid decrease in BMD, increased bone marrow FF and decreased blood flow perfusion. Decreased blood perfusion is one of the mechanisms of osteoporosis. Due to dysfunction of bone marrow microcirculation, vascular endothelial cells are closely connected and the late stage is caused by the accumulation of bone marrow fat and microvascular pressure. It is indicated that DCE-MRI plays a role in osteoporosis therapy targets or early assessment of efficacy.

The limitations of this study were as follows: (1) quantitative DCE-MRI is complex and time-consuming and may increase the errors of parameter evaluation; (2) the choice of different pharmacokinetic models and analysis software would lead to differences in measurement data ${ }^{11,27}$; (3) there is a lack of strict design of the pathology-image for a control study.

A cross-sectional study of postmenopausal women found that BMD decreased with age. Bone mineral density of the vertebrae can detect osteoporosis earlier. Similarly, $K^{\text {trans }}, K_{e p}$ and $V_{e}$ values of the lumbar spine were negatively correlated with age. The decrease of $\mathrm{K}^{\text {trans }}, \mathrm{K}_{\mathrm{ep}}$ and $V_{e}$ values in the lumbar spine were associated with a decrease of BMD, and were positively correlated with BMD of the lumbar spine. $K^{\text {trans }}, K_{e p}$ and $V_{e}$, bone mass reduction and osteoporosis were reduced, suggesting that bone marrow cavity fat was increased and tissue space and microcirculation were reduced. These will be useful for early diagnosis of osteoporosis and provide a reference for treatment of this condition.

\section{Conclusions}

The incidence of bone loss and osteoporosis increases with age. The measurement of BMD was conducive to early diagnosis of osteoporosis. The $\mathrm{K}^{\text {trans }}, \mathrm{K}_{\mathrm{ep}}$ and $\mathrm{V}_{\mathrm{e}}$ values of lumbar vertebrae decreased with age and have a positive correlation with lumbar BMD. This shows the potential value of DCE-MRI in the diagnostic algorithm of osteoporosis.

\section{References}

1. Langdahl B, Ferrari S, Dempster DW. Bone modeling and remodeling: Potential as therapeutic targets for the treatment of osteoporosis. Ther Adv Musculoskelet Dis. 2016;8(6):225-235.

2. Lv H, Jiang F, Guan D, et al. Metabolomics and its application in the development of discovering biomarkers for osteoporosis research. Int J Mol Sci. 2016;17(12). Pii: E2018.

3. Cauley JA. Osteoporosis: Fracture epidemiology update 2016. Curr Opin Rheumatol. 2017;29(2):150-156.

4. Yoshiki F, Nishikawa A, Taketsuna M, Kajimoto K, Enomoto H. Efficacy and safety of teriparatide in bisphosphonate-pretreated and treatment-naive patients with osteoporosis at high risk of fracture: Post hoc analysis of a prospective observational study. J Orthop Sci. 2017;22(2):330-338.

5. Shehata AS, Amer MG, Abd El-Haleem MR, Karam RA. The ability of hesperidin compared to that of insulin for preventing osteoporosis induced by type I diabetes in young male albino rats: A histological and biochemical study. Exp Toxicol Pathol. 2017;69(4): 203-212.

6. Bell KJ, Hayen A, Glasziou P, et al. Potential usefulness of BMD and bone turnover monitoring of zoledronic acid therapy among women with osteoporosis: Secondary analysis of randomized controlled trial data. J Bone Miner Res. 2016;31(9):1767-1773.

7. Popp AW, Meer S, Krieg MA, Perrelet R, Hans D, Lippuner K. Bone mineral density (BMD) and vertebral trabecular bone score (TBS) for the identification of elderly women at high risk for fracture: The SEMOF cohort study. Eur Spine J. 2016;25(11):3432-3438.

8. Miyauchi A. Relationship of pharmacokinetics, changes of bone turnover markers and BMD/fractures efficacy during treatment with anabolic agents: Teriparatide daily and once weekly subcutaneous injections [in Japanese]. Clin Calcium. 2016;26(11):1583-1595.

9. Compston J. Bone quality: What is it and how is it measured? Arq Bras Endocrinol Metabol. 2006;50(4):579-585.

10. Su Y, Leung J, Hans D, Aubry-Rozier B, Kwok T. Added clinical use of trabecular bone score to BMD for major osteoporotic fracture prediction in older Chinese people: The Mr. OS and Ms. OS cohort study in Hong Kong. Osteoporos Int. 2017;28(1):151-160.

11. Ma HT, Griffith JF, Zhao X, Lv H, Yeung DK, Leung PC. Relationship between marrow perfusion and bone mineral density: A pharmacokinetic study of DCE-MRI. Conf Proc IEEE Eng Med Bio/ Soc. 2012;2012: 377-379.

12. Griffith JF, Wang YX, Zhou H, et al. Reduced bone perfusion in osteoporosis: Likely causes in an ovariectomy rat model. Radiology. 2010; 254(3):739-746.

13. Leslie WD, Majumdar SR, Morin SN, Hans D, Lix LM. Change in trabecular bone score (TBS) with antiresorptive therapy does not predict fracture in women: The Manitoba BMD Cohort. J Bone Miner Res. 2016;32(3):618-623.

14. Basu S, Houseni M, Bural G, et al. Magnetic resonance imaging based bone marrow segmentation for quantitative calculation of pure red marrow metabolism using 2-deoxy-2-[F-18]fluoro-D-glucose-positron emission tomography: A novel application with significant implications for combined structure-function approach. Mol Imaging Biol. 2007;9(6):361-365.

15. Sheu Y, Cauley JA. The role of bone marrow and visceral fat on bone metabolism. Curr Osteoporos Rep. 2011;9(2):67-75.

16. Li GW, Tang GY, Liu Y, Tang RB, Peng YF, Li W. MR spectroscopy and micro-CT in evaluation of osteoporosis model in rabbits: Comparison with histopathology. Eur Radiol. 2012;22(4):923-929. 
17. Griffith JF, Wang YX, Zhou H, et al. Reduced bone perfusion in osteoporosis: Likely causes in an ovariectomy rat model. Radiology. 2010; 254(3):739-746

18. Liu Y, Cao L, Hillengass J, et al. Quantitative assessment of microcirculation and diffusion in the bone marrow of osteoporotic rats using VCT, DCE-MRI, DW-MRI, and histology. Acta Radiol. 2013;54(2): 205-213.

19. Ma HT, Lv H, Griffith JF, Yuan J, Leung PC. Bone marrow perfusion of proximal femur varied with BMD: A longitudinal study by DCEMRI. Conf Proc IEEE Eng Med Biol Soc. 2013;2013:2607-2610.

20. Griffith JF, Yeung DK, Antonio GE, et al. Vertebral marrow fat content and diffusion and perfusion indexes in women with varying bone density: MR evaluation. Radiology. 2006;241(3):831-838.

21. Griffith JF, Yeung DK, Antonio GE, et al. Vertebral bone mineral density, marrow perfusion, and fat content in healthy men and men with osteoporosis: Dynamic contrast-enhanced MR imaging and MR spectroscopy. Radiology. 2005;236(3):945-951.

22. Biffar A, Schmidt GP, Sourbron S, et al. Quantitative analysis of vertebral bone marrow perfusion using dynamic contrast-enhanced MRI: Initial results in osteoporotic patients with acute vertebral fracture. J Magn Reson Imaging. 2011;33:676-683.
23. Ma HT, Lv H, Griffith JF, et al. Bone marrow perfusion of proximal femur varied with BMD: A longitudinal study by DCE-MRI. Conf Proc IEEE Eng Med Biol Soc. 2013;2013:2607-2610.

24. Breault SR, Heye T, Bashir MR, et al. Quantitative dynamic contrastenhanced MRI of pelvic and lumbar bone marrow: Effect of age and marrow fat content on pharmacokinetic parameter values. AJR Am J Roentgenol. 2013;200(33):W297-303.

25. Zhu JQ, Zhang L, Tang GY, et al. Vertebral blood perfusion and its likely causes: A quantitative dynamic contrast-enhanced MR imaging study of a rat osteoporosis model. Radiology. 2017;282:369-380.

26. Wáng $Y X$, Griffith JF, Deng M, et al. Rapid increase in marrow fat content and decrease in marrow perfusion in lumbar vertebra following bilateral oophorectomy: An MR imaging-based prospective longitudinal study. Korean J Radiol. 2015;16(1):154-159.

27. Song Y, Cho G, Suh JY, et al. Dynamic contrast-enhanced MRI for monitoring antiangiogenic treatment: Determination of accurate and reliable perfusion parameters in a longitudinal study of a mouse xenograft model. Korean J Radiol. 2013;14(4):589-596. 